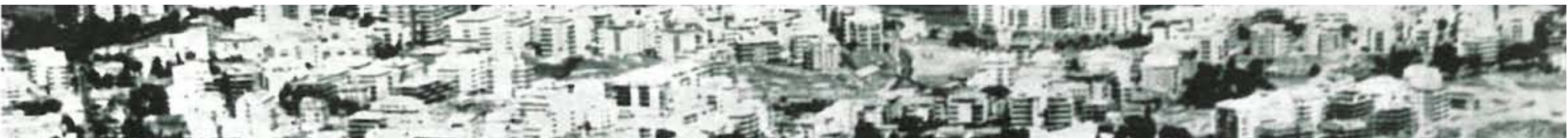

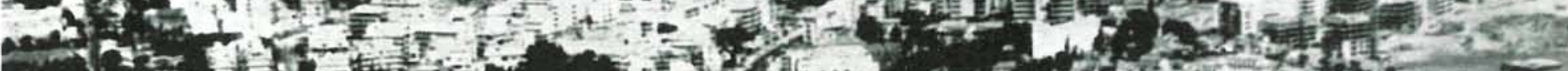

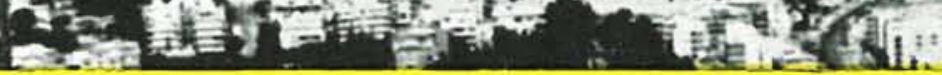

\title{
viaducto olímpico de Roma
}

P. L. NERVI, ingeniero

(1)

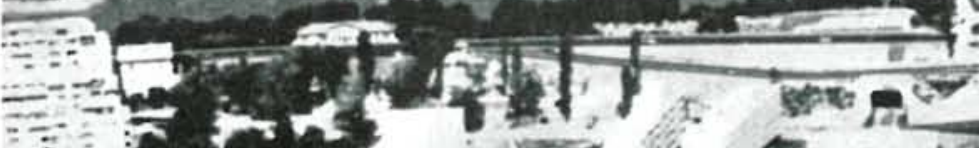

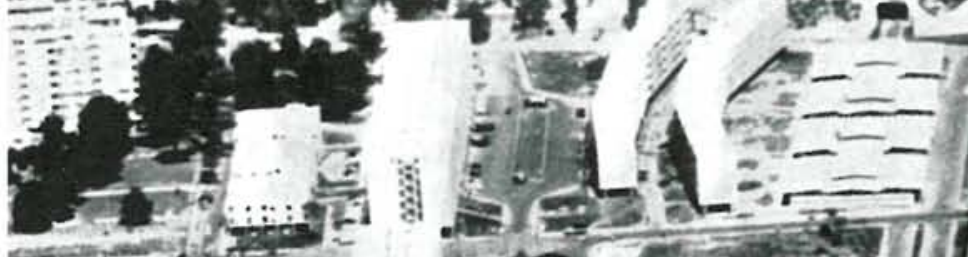

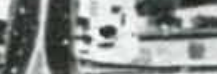

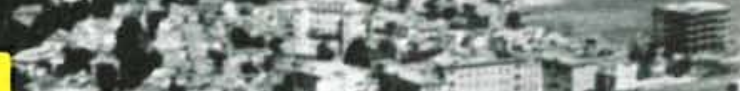
1.

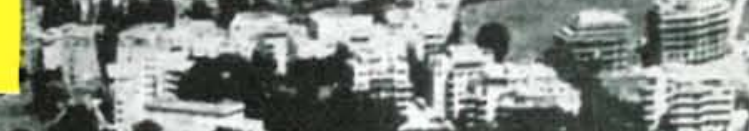

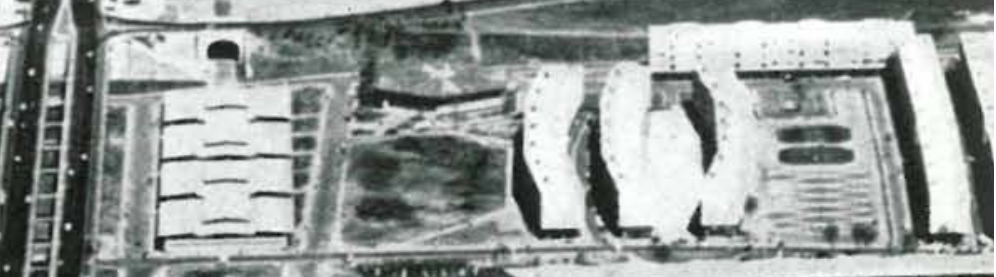

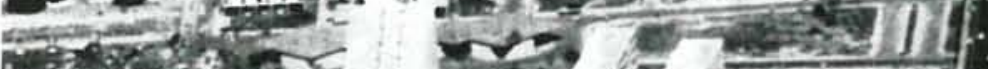

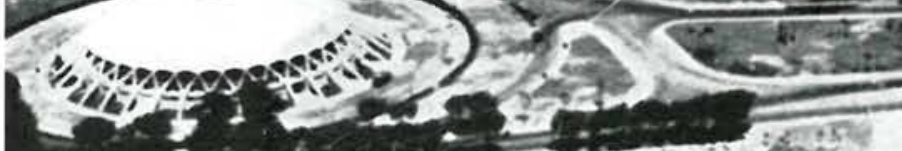

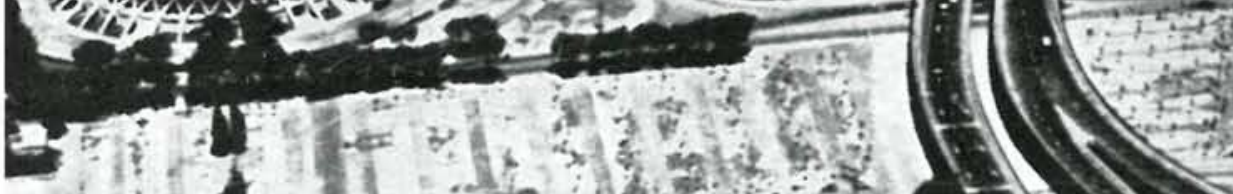

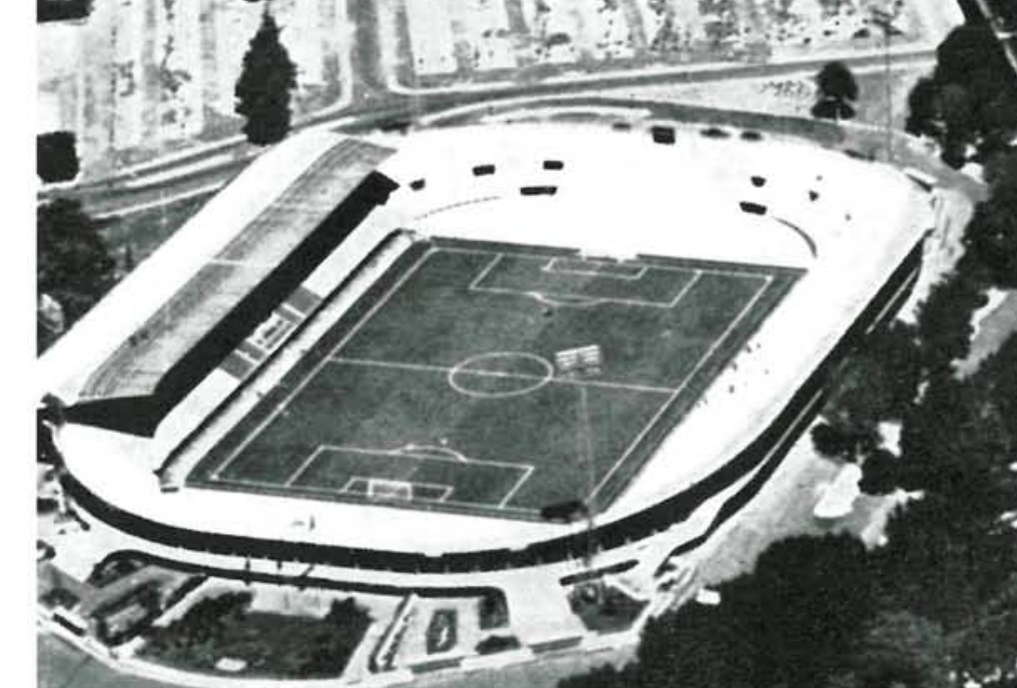

A

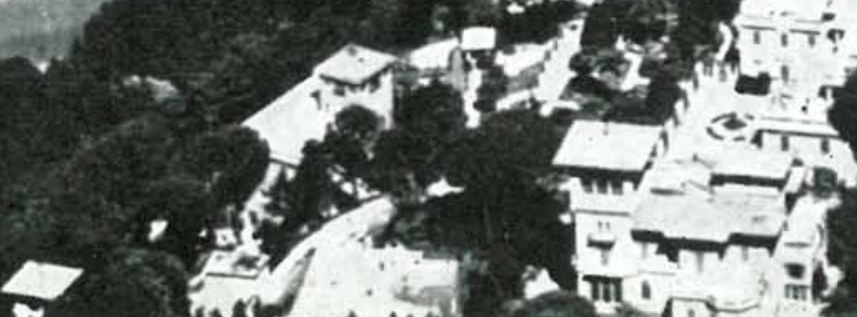

$\frac{1}{(2)}$

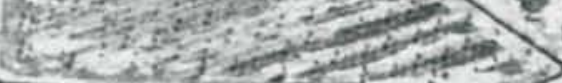
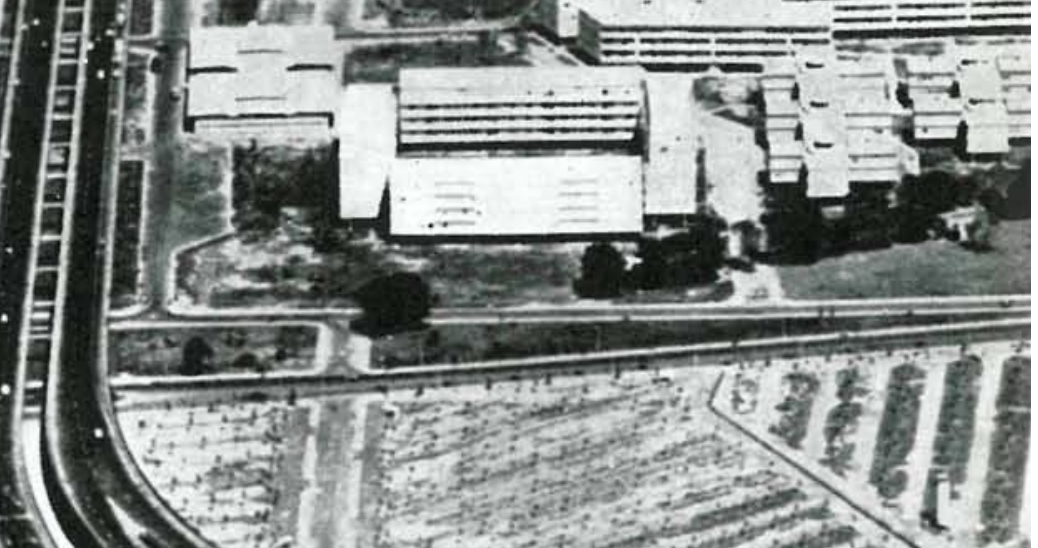

i.

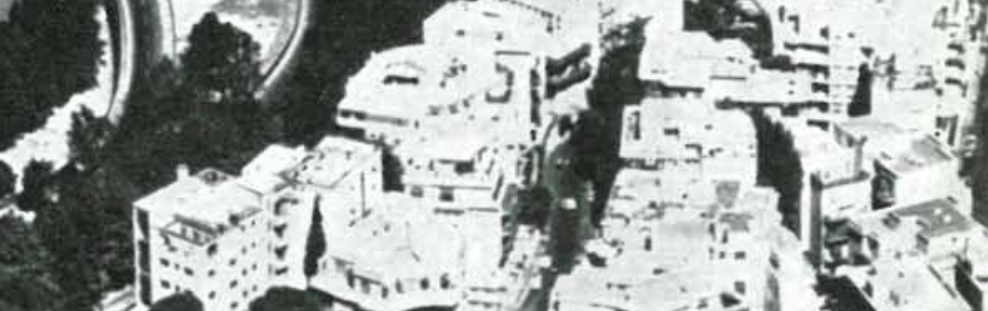

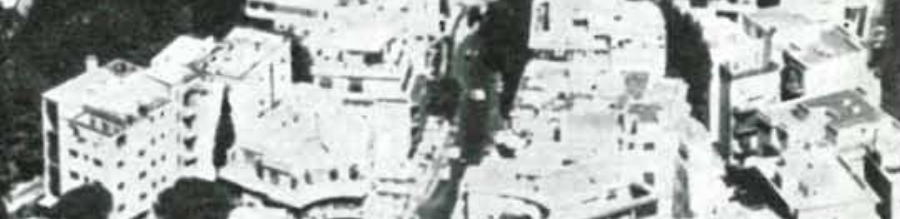

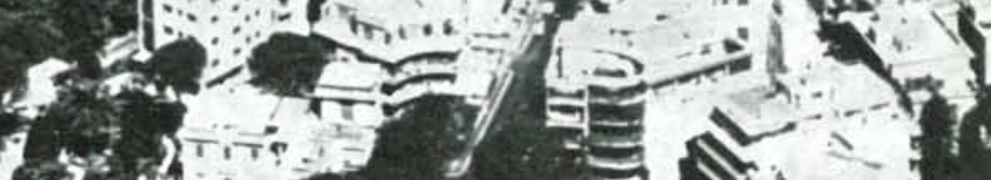

a 


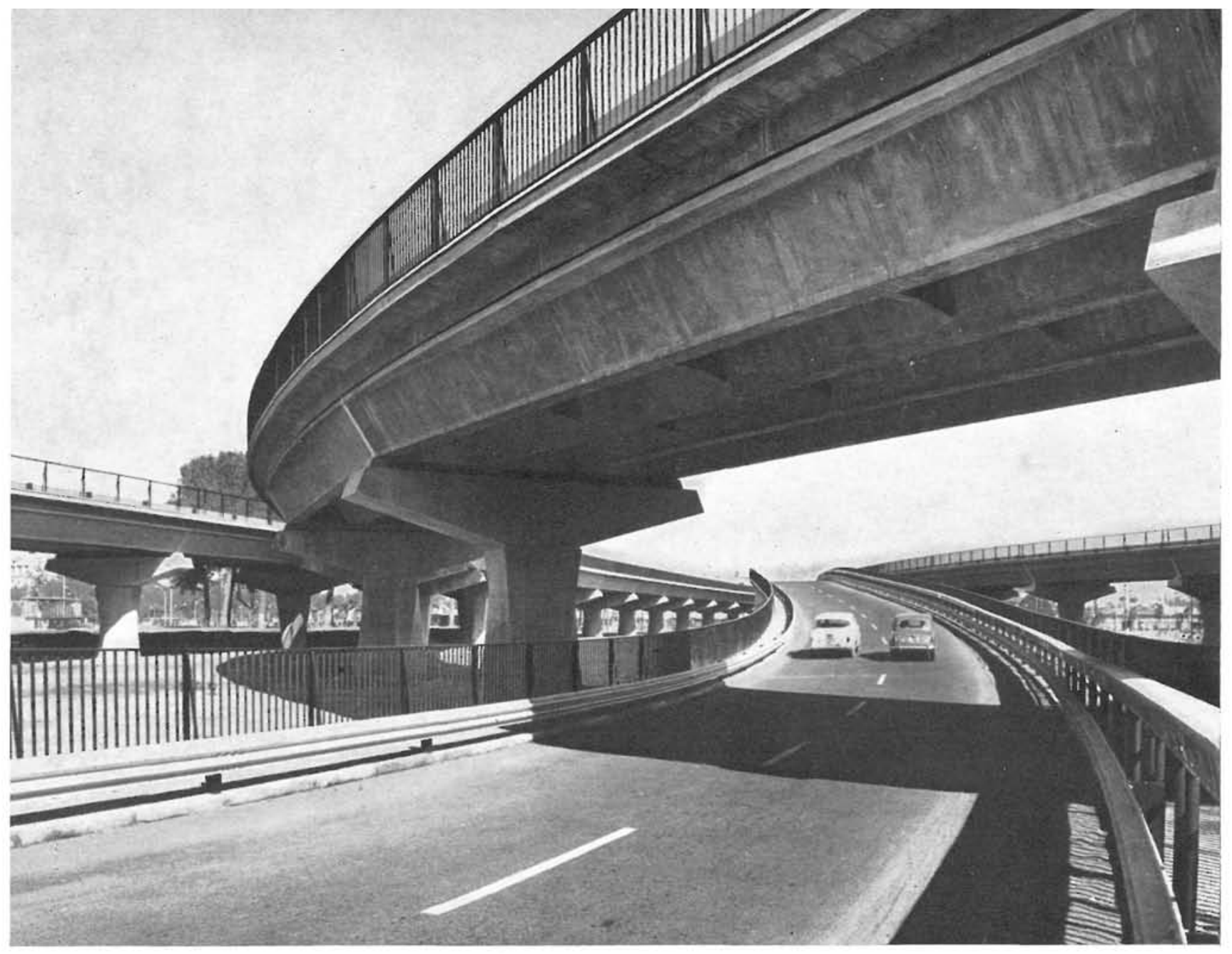

$562-68$

Con motivo de la última olimpíada, celebrada en Roma (Italia), se tuvo que hacer frente al problema que presentaban los transportes y comunicaciones. El acceso a esta zona olímpica, además de no ser suficiente, necesitaba de vías que encauzaran el tráfico y se prestasen a absorber el volumen del mismo, que con motivo de reuniones deportivas se crea, y como complemento ulterior, dotar de accesos permanentes a esta zona que debía ser aprovechada después de estos cometidos como una amplia extensión residencial.

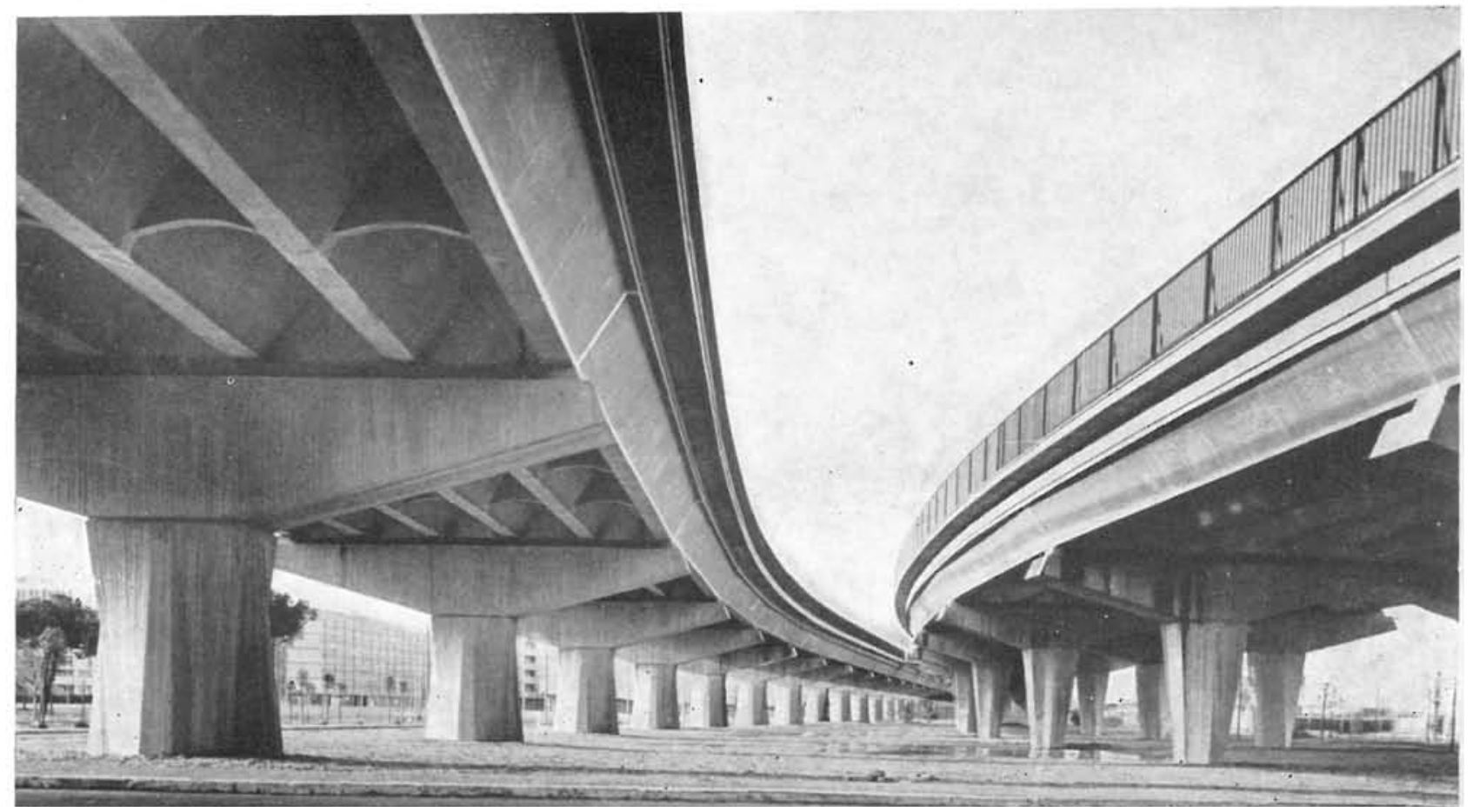




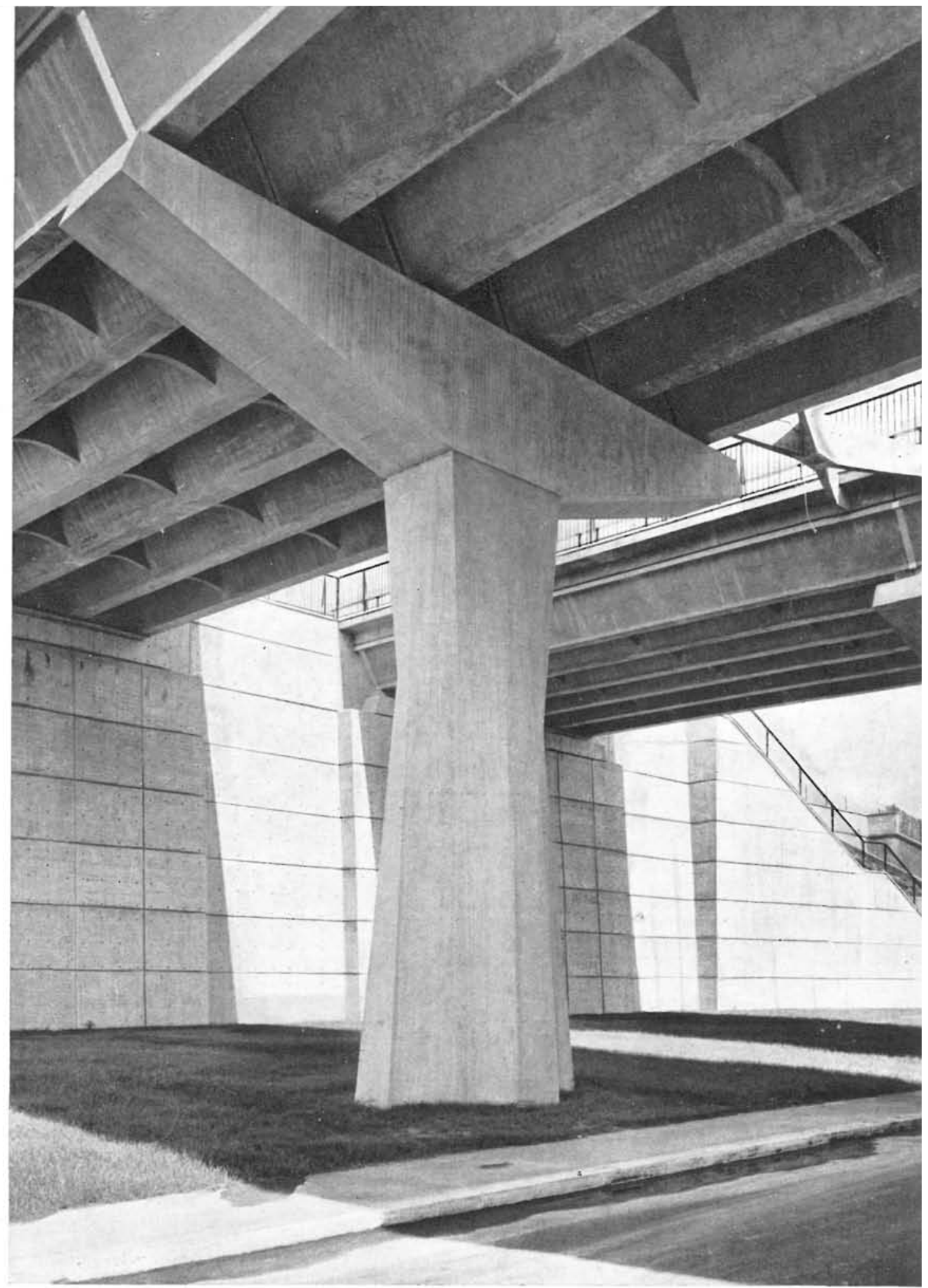

Los pasos superiores en las grandes ciudades han sido el resultado inmediato a soluciones apremiantes que el tráfico rodado urbano plantea. Estas soluciones tienen un doble favor: uno, por encauzar automáticamente el tráfico en volumen, y el otro, por permitir a la superficie sobre la que pasa su utilización como parque, jardines o en calzadas y aceras habilitadas también al tráfico.

El paso superior del Corso-Francia se apoya sobre soportes de único fuste, de forma graciosa en línea, evitando así las palizadas encombrosas que dejan la superficie inferior en apurada condición para sacar provecho práctico de ella. 


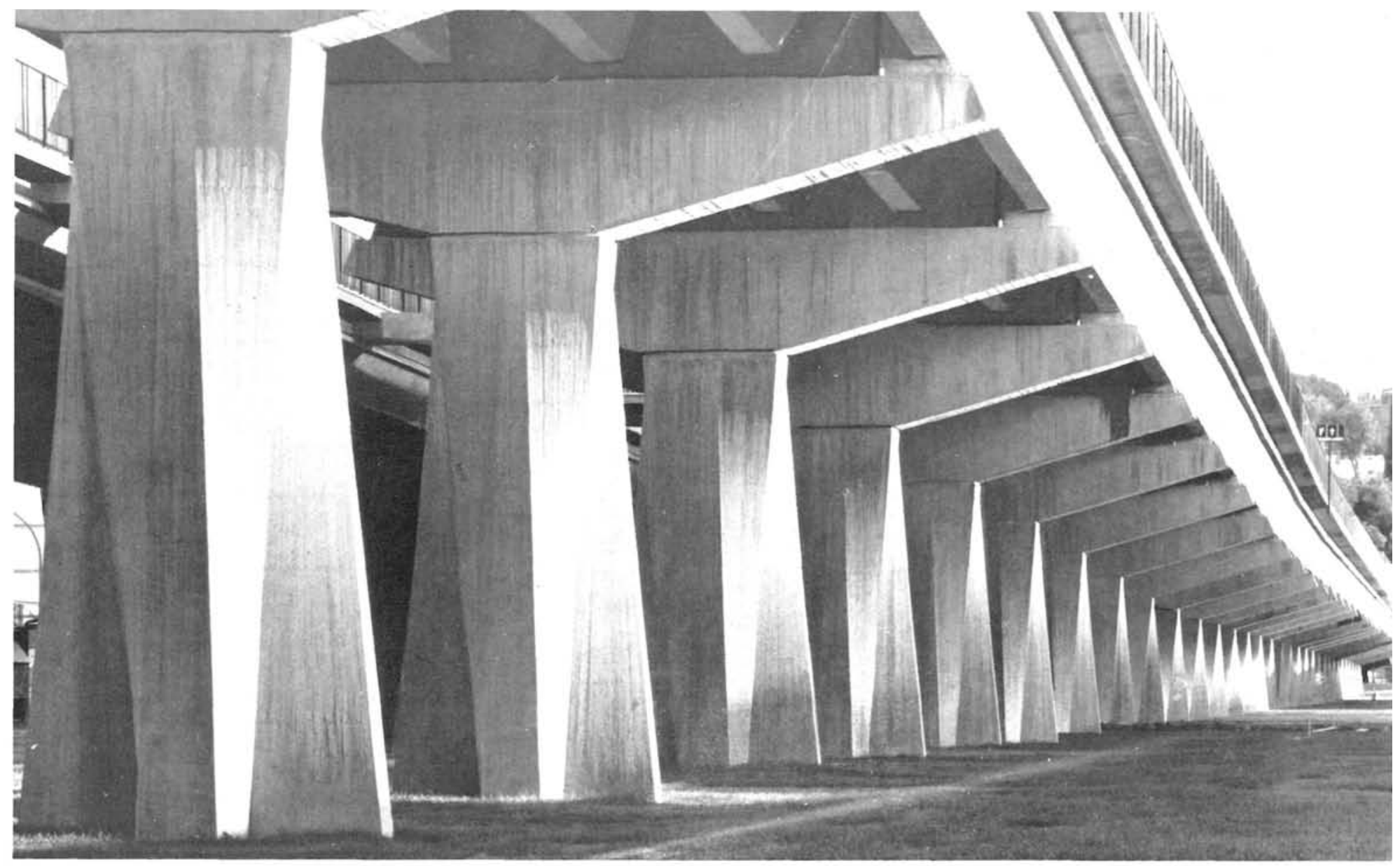

Estos soportes, espaciados a $16 \mathrm{~m}$, tienen en su base una sección cruciforme, de altura variable de 3,5 a $8 \mathrm{~m}$. En su parte superior se termina por un cabezal que vuela a uno y otro lado del eje de la calzada. La base descansa sobre un bloque de hormigón, cuya capacidad de sustentación se ha mejorado mediante el empleo de pilotes. Todos estos elementos son de hormigón armado, cuyas caras vistas se han dejado con las superficies naturales del desencofrado sin más tratamiento que el chorro de arena fina para limpiar las manchas que inevitablemente aparecen en obra.

El paso superior está constituido por dos calzadas independientes de $10 \mathrm{~m}$ de anchura cada una, provistas de andenes, para peatones. Espaciadas a $48 \mathrm{~m}$, se han dejado una serie de pasarelas que salvan los $5 \mathrm{~m}$ de luz que forman los bordes interiores de las calzadas. Estas pasarelas permiten el acceso de los peatones a las dos calzadas. Las calzadas tienen una pendiente longitudinal del 2 por 100 .

Para formar el tablero de las calzadas se han prefabricado una serie de vigas, longitudinales, de sección hueca en forma triangular. Estas vigas, de $16 \mathrm{~m}$ de longitud y 16 toneladas de peso cada una, se han pretensado con armaduras de acero semiduro.

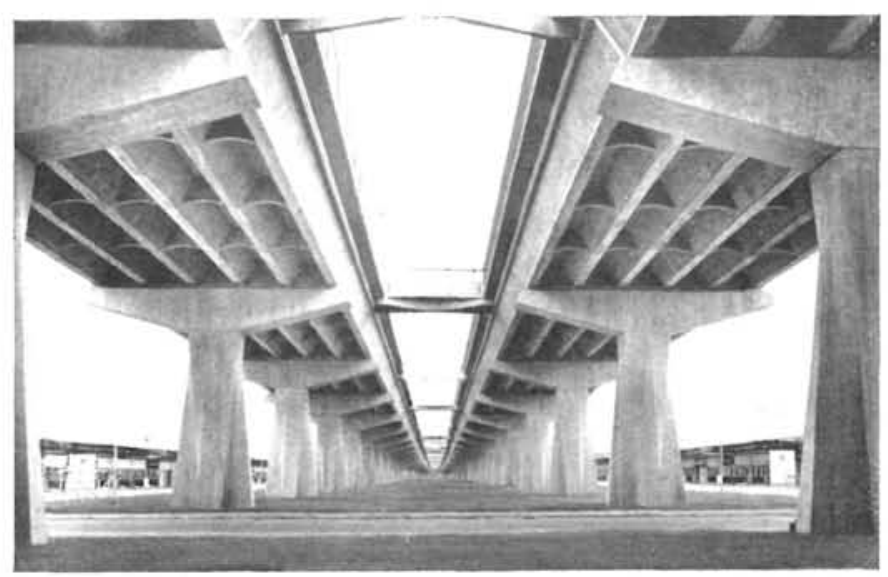

Cada calzada tiene 6 vigas longitudinales cuyas paredes superiores constituyen el firme de la calzada. Al prefabricar estos elementos se les dio forma de V, cuya parte su. perior se cerró, después de colocarlas, por medio de losas hormigonadas en obra. Los andenes se han formado sobre ménsulas que sobresalen de ambos lados de cada una de las calzadas. Todos estos elementos huecos disponen de diafragmas con objeto de ganar rigidez.

En las extremidades de cada una de estas dos calzadas se bifurcan constituyendo dos direcciones distintas. En estas partes el trazado no es rectilíneo, pues forma una curva particular de acuerdo con los puntos en que desem. bocan.

Las aguas de lluvia se recogen en sumideros, de los que a través de tubos de gres descienden por el interior de los soportes hasta desaguar en el alcantarillado.

El aspecto general de esta obra, a pesar de su carácter en elevación, armoniza con la urbanización de la zona que atraviesa, destacando por su propia estética.

Fotos: OSCAR SAVIO, G. GHERARDI Y A. FIOREU 